\title{
Part-time senior registrar training in child and adolescent psychiatry
}

\author{
Ann Gath, Consultant Psychiatrist, Hilda Lewis House, The Bethlem Royal Hospital, \\ Shirley, Croydon
}

\begin{abstract}
An enquiry concerning the difficulties faced by doctors with domestic responsibilities was undertaken as a response to a letter by a part-time senior registrar who was facing problems in her training.

Using the records held by the Child \& Adolescent Psychiatry Specialist Advisory Committee (CAPSAC) of the Joint Higher Psychiatric Training Committee (JCHPT), 12 women were identified who were doing part-time training which had been approved under the Government Circular PM(79)3. They were sent a questionnaire, a copy of which is to be found in the Appendix. Eight returned completed questionnaires. One was in hospital for a long period because of complications in pregnancy and three did not reply. There is no record of a man doing higher training on a part-time basis in child and adolescent psychiatry.
\end{abstract}

\section{Training commitment}

The time the respondents had spent in training parttime ranged from two weeks to four years, with a mean of two years. Four did four regular clinical sessions, three did five and one did six sessions. All the respondents had a session for academic teaching. In three cases this section was expected to cover research as well, but five women had one session that was regularly put aside for research. Seven did regular 'On Call Duty', and two took part in the weekend rota. All but one were working more sessions than those for which they were paid. Only one said she did not do this, and explained that she had been forewarned that some advantage would be taken of her part-time status. This respondent had recently changed from being full-time to part-time. Everyone else found it necessary to work overtime to get the clinical work done, and also to attend case conferences, etc.

Six of the women who returned completed questionnaires expected their training to finish within the next two to two and a half years. One, however, did not know when she would be regarded as trained, and another expected to have finished her training in 1995 !

\section{Quality of training}

In general, there was satisfaction with the quality of training. Three respondents described their training as very good and three others as satisfactory or good. One divided her response, describing her training as academically excellent, and clinically reasonable. The least experienced, very sensibly, reserved her judgement. The majority, six, thought they had as good training opportunities as other, full-time, senior registrars. One of these six was doubtful about the quality of academic training, but felt that she was no different in this respect from the other full-time senior registrars in the same region. The remaining two were concerned that their academic teaching was not as good as it should be. Again the majority, six, found no problem in getting to College meetings. All those who answered our enquiries said they had access to a good library.

\section{Problems of part-time training}

The problems encountered were varied. Distance played a part. Sometimes the distance was a major problem because of working in a rural area, meaning that the part-time doctor had to drive many miles a day. However, this was not confined to rural areas and one London based doctor had hours of driving to face too. Distance from home made it sometimes difficult to work in different settings. However, the distances travelled varied. One doctor travelled 15 miles to the clinic base and 45 miles to the academic centre. Two others travelled more than 10 miles to their main base but the rest were within reasonable distance.

More serious problems had been encountered in the attitude of their colleagues. Three of the parttime doctors felt that they were considered secondclass merely because they were part-time. For example, a former full-time senior registrar said "I was made to feel I was not doing a proper job." For others there was no office space provided and several said they were given many minor responsibilities and left to get on with it. 


\section{Career aspirations}

So far, only two had applied for a consultant post and one of these had been successful in her application just days after filling in the questionnaire. Four of those working part-time had never worked full-time as a senior registrar but two had already done more than two years in full-time higher training before they moved into part-time work.

The career aspirations were varied. Three were hoping for a part-time consultant post but three others intended to work full-time, and two wisely kept an open mind according to the opportunities and their personal commitments when they were ready. Five of them had been given some advice on careers. One of them was particularly appreciative of advice to her which had been "Do what you enjoy doing". She had found this helpful and was much enjoying her training and looking forward with reasonable optimism. However, only two had actually looked ahead to see what job they could see would arise, and where. Only one of these part-time doctors had ever been advised to change her speciality. In her case, she was advised to change to psychogeriatrics, a shortage area, particularly in her region. However, it was this senior registrar who had just obtained a fulltime consultant appointment.

All the doctors training part-time in child and adolescent psychiatry had family commitments. All of them had children who ranged from age three months to 12 years, and a family size between one and three, with the mean, of course, as in all surveys, of two. Most of the families were, however, fairly closely spaced. All their husbands were in professions. Two husbands were medical and two were also employed in the Health Service in other capacities. Six of the husbands were in permanent jobs, two of whom described themselves as permanently stuck where they were. However, another husband, a senior registrar himself, was at present looking for a consultant job which could be located anywhere. Two of the women had other domestic commitments, i.e. a frail parent-in-law in both cases. Only two of the eight had had maternity leave while actually on the training scheme, and all of them were themselves healthy, with the exception of the one who was at the time in hospital with complications of pregnancy.

\section{Organisation of part-time training}

The most consistent criticism was the long time that was required to get the procedure of the $\operatorname{PM}(79) 3$ moving. It is also clear that there is a need for much more actual career advice, both initially on embarking on the part-time training, and when coming towards the end.
Not all the comments agreed with each other. There were some conflicting statements, for example, about uncertainty and future placements on the scheme. In one case, this appeared to be due to the fact that the consultants concerned had had no previous experience of part-time training. However, the opposite was true in another case where the scheme was kept deliberately flexible. Even the change from full-time to part-time was experienced very differently by those two senior registrars who had recently done so. One accomplished the change happily but the other found it difficult and clearly felt downgraded.

It was serious that two of the doctors doing their senior registrar training on a part-time basis felt that they were exploited, and were in fact doing as much clinical work as full-time colleagues, but lacked the advantage of status, and other privileges, as well as that of a full-time salary. Indeed, looking at their obligations, their chances for study, etc, it would appear that these two women were being most unfairly treated.

\section{Comments}

To conclude, these are a group of well-qualified, highly motivated trainees. The problems that they have experienced are sometimes to do with personal circumstances, particularly the difficulty of not being able to move to seek a full training post, usually because of the husband's occupation. Thus, they may find themselves in an area which is not conveniently situated near an existing good scheme.

The remedial problems are the lack of career advice, and in the minority of cases, both in established approved schemes, of unimaginative treatment by organisers which verges on exploitation.

The latter problem of possible exploitation can be dealt with by CAPSAC on their subsequent visits to those particular schemes. Indeed, all members of the Committee have been alerted to look for part-time training and to see that the opportunities and the duties are fairly distributed. To address the other problem of career advice, it has been suggested that a support group should be available. This support group must include some who have had their higher training part-time, and who have recently been appointed as consultants. Such a support group, which could be contacted through the College, could offer career advice and occasional support for which there is clearly a need.

\section{Acknowledgement}

I am most grateful to the very busy women who completed the questionnaire. 


\section{Appendix}

NAME:

ADDRESS:

\section{PRESENT POST:}

A: Training:

1. How long have you been training as a senior registrar?

2. How many sessions do you work a week?
(a) Clinical
(b) Academic Training
(c) Research

3. Do you do any on-call duty?

4. Do you find it necessary to work over and above your official sessions?

Pressure of work

YES/NO

To fit in case conference, etc.

YES/NO

5. When is your training due to finish?

6. What is your opinion of your training so far?

7. Are you getting the same range of training opportunities as full-time colleagues?

(a) Clinical

(b) Academic

(c) Additional experiences, e.g. opportunity of attending courses, meetings, etc.

(d) Research

8. Can you get to meetings outside the region? e.g. Section Spring Scientific Meeting or other College Meetings?

9. Have you access to a good library?

10. What are the main problems which you have encountered?
11. How far do you have to travel?

(a) To your clinical base

(b) For your academic sessions

12. Have you applied yet for any consultant posts?

13. Have you done any of your senior registrar training full-time?

If so, for how long?

14. Do you intend continuing to work part-time as a consultant?

15. Have you had any career advice since starting on the scheme?

16. If you can not move, do you know of possible job vacancies?

17. If there are few prospects in your area, have you been advised to stick it out in your chosen speciality or have you been advised to change, e.g. to psychogeriatrics?

B: Please will you kindly give us some information about your family and domestic circumstances?

1. Number and ages of children:

2. Partner's occupation:

3. Is your partner likely to need to move to find a permanent post?

4. Have you any other domestic ties, e.g. elderly parent requiring care?

5. Since coming on the scheme have you had any maternity leave?

6. Have you had any health problems since you have been on the scheme?

Please let us know of any other points you think are relevant to the planning of part-time higher training in child and adolescent psychiatry.

\title{
Coordinating care Homepack: The use of a computer in community care
}

\author{
D. N. Martindale, Project Coordinator; M. Ness, Nurse Project Officer, \\ Coordinating Care Project, Community Psychiatry Research Unit; T. H. TURNER, \\ Consultant Psychiatrist, Psychiatric Day Hospital; and J. WRIGHT, Community \\ Development Worker, Psychiatric Day Hospital, Hackney Hospital, London E9
}

The project described in this paper developed from a DHSS funded scheme which was part of the Government's 'Helping the Community to Care' initiative. This was aimed at meeting a deficiency in the community - the lack of a coordinated system of after care for people suffering from long-term mental illness. The Mental Health Division of the DHSS described it thus:
"... Research and development work had already shown that by providing support, e.g. by providing relatives and patients themselves with basic information about the nature of the disorder and sources of help, the relapse rate can be reduced and also the strain on the carers. ..."1 